Western University

Scholarship@Western

Aboriginal Policy Research Consortium International (APRCi)

2011

\title{
Both ways strong: using digital games to engage Aboriginal learners
}

Robyn Jorgensen

Griffith University

Tom Lowrie

Charles Sturt University

Follow this and additional works at: https://ir.lib.uwo.ca/aprci

Part of the Curriculum and Instruction Commons, and the Educational Methods Commons

Citation of this paper:

Jorgensen, Robyn and Lowrie, Tom, "Both ways strong: using digital games to engage Aboriginal learners" (2011). Aboriginal Policy Research Consortium International (APRCi). 413.

https://ir.lib.uwo.ca/aprci/413 
This article was downloaded by: [University of Western Ontario]

On: 30 October 2012, At: 09:32

Publisher: Routledge

Informa Ltd Registered in England and Wales Registered Number: 1072954 Registered

office: Mortimer House, 37-41 Mortimer Street, London W1T 3J H, UK

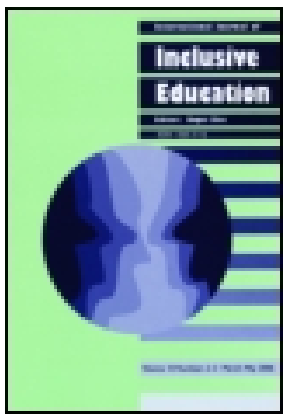

\title{
International J ournal of Inclusive Education
}

Publication details, including instructions for authors and subscription information:

http:// www. tandfonline.com/loi/ tied20

\section{Both ways strong: using digital games to engage Aboriginal learners}

\author{
Robyn J orgensen ${ }^{a} \&$ Tom Lowrie ${ }^{b}$ \\ a Griffith Institute for Educational Research, Griffith University, \\ Brisbane, QLD, Australia \\ ${ }^{\mathrm{b}}$ Research Institute for Professional Practice, Learning and \\ Education, Charles Sturt University, Wagga Wagga, NSW, Australia \\ Version of record first published: 16 Nov 2011.
}

To cite this article: Robyn J orgensen \& Tom Lowrie (2011): Both ways strong: using digital games to engage Aboriginal learners, International J ournal of Inclusive Education, DOI: 10.1080/ 13603116. 2011.605912

To link to this article: http:// dx. doi.org/ 10.1080/ 13603116. 2011.605912

\section{GFirst}

\section{PLEASE SCROLL DOWN FOR ARTICLE}

Full terms and conditions of use: http://www.tandfonline.com/page/terms-andconditions

This article may be used for research, teaching, and private study purposes. Any substantial or systematic reproduction, redistribution, reselling, loan, sub-licensing, systematic supply, or distribution in any form to anyone is expressly forbidden.

The publisher does not give any warranty express or implied or make any representation that the contents will be complete or accurate or up to date. The accuracy of any instructions, formulae, and drug doses should be independently verified with primary sources. The publisher shall not be liable for any loss, actions, claims, proceedings, demand, or costs or damages whatsoever or howsoever caused arising directly or indirectly in connection with or arising out of the use of this material. 


\title{
Both ways strong: using digital games to engage Aboriginal learners
}

\author{
Robyn Jorgensen $^{\mathrm{a} *}$ and Tom Lowrie ${ }^{\mathrm{b}}$ \\ ${ }^{a}$ Griffith Institute for Educational Research, Griffith University, Brisbane, QLD, Australia; \\ ${ }^{b}$ Research Institute for Professional Practice, Learning and Education, Charles Sturt \\ University, Wagga Wagga, NSW, Australia
}

(Received 29 May 2011; final version received 30 May 2011)

\begin{abstract}
Engaging Aboriginal learners in the school curriculum can be quite a challenge given issues of cultural and linguistic differences. Even more so, these differences can be expanded when the students are in their adolescence. Creating learning environments that engage learners, while providing deep learning opportunities, is one of the biggest challenges for teachers in remote communities. This paper reports on a reform initiative that centred on the use of a digital game, Guitar Heroes, in a remote Aboriginal school. It was found that the digital media provided teachers with opportunities for new learning spaces and resulted in additional unintended learning outcomes.
\end{abstract}

Keywords: Aboriginal; digital games; engagement; mathematics

\section{Introduction}

International and national test results have consistently shown that the Australian students who are performing most poorly in literacy and numeracy are remote Aboriginal students (Council of Australian Governments [COAG] Reform Council 2010; De Bortoli and Thomson 2009). While some criticism may be made of such testing, the performances are indicative of very poor levels of literacy and numeracy for Aboriginal learners. The reasons for such poor performance are varied but include the substantial differences in cultures and languages between the home and school for these students and poor and irregular attendance of students which impacts on the potential for learning.

Community life in remote Australia is austere and often deplete of the usual literacy and numeracy cues found in mainstream, urban contexts. Communities do not have the signposts found in urban Australia. There are no street signs, no numbers on houses, little to no advertising materials, infrequently prices are not attached to goods in the local store, few people know their birthdates or ages, few people have home phones and few, if any, communities have magazines or newspapers delivered. These cues often immerse young children in the worlds in which they live so that literacy and numeracy are an integral part of their lifeworlds. This cannot be said for most remote communities.

${ }^{*}$ Corresponding author. Email: r.jorgensen@griffith.edu.au 
The cultures of Aboriginal people are often starkly different from those of mainstream (non-Aboriginal) Australia. Not only in terms of belief systems but also patterns of communication are often different, as are views on science and spirituality, and logical/mathematical thinking. As culture shapes ways of seeing and acting in the social world, it is not surprising that there are many differences between the world views of Aboriginal students and those represented in and through the school curriculum. For example, in some of the cultures, the need for counting is very limited. In Pitjantjatjara, which is the predominant language of the communities where this research was conducted, the counting language is one, two, three and then 'big mob' for collections greater than three. This language shapes the mathematical lifeworlds for the students but is also shaped by their lifeworlds. Few things exist in large groups in the stark desert habitat. Similarly, there are no explicit words for comparisons (such as bigger, smaller) but such comparisons are expressed through intonations or actions. The extended sound of long (e.g. lo-o-o-o-o-ng) is used to indicate that an object or site is further than a site that is expressed through a contracted expression of long. However, in contrast, there is a very rich language of location. There are only seven prepositions in Pitjantjatjara whereas there are more than 60 in English thus making it difficult to do exact translations in some terms (such as on, above, etc.) where the terms are similar but different in meaning. The needs of the people have been reflected or shaped by their language. But this language is very different from the language of instruction not only in terms of concepts but also in the ways of interacting. For many remote Aboriginal cultures, there are strict rules of who is able to speak to whom and what can be the topic/s of conversation. Most salient in the context of secondary education where this study was conducted are the very strict gender and familial rules of interaction. Such rules around social interaction impact on how classroom interactions can be undertaken.

In the Northern Territory, where this research was conducted, there are approximately 50 Aboriginal languages (Harris 1994). In the dozen or so larger communities, some of these languages may be spoken by 500-3000 speakers. In most of the remote communities, the language of school instruction is English. Although there were movements for bi-cultural/bi-lingual programmes that were commenced in 1972, these were axed in 2008. At the time of writing this paper, all instruction in the Northern Territory was to be in English. However, in most communities, English is spoken by students when they are in school or in contexts where they are talking to non-Aboriginal people. When interacting with their own people, the students speak their home languages. Often they can speak more than one Aboriginal language. Hence, in these contexts, English should be considered a foreign language rather than a second language since it is mainly used only in the formal school context.

Culturally, the ways of learning are quite different from school learning where there is often direct instruction done by the teacher and where the students are expected to demonstrate the skills or behaviour modelled by the teacher, and where risk taking is a valued disposition. However, in desert life, there are very limited resources so learning by observation and then having an attempt at making the object (such as a spear) is undertaken when the learner is confident that he/she will not make a public error or when resources will not be wasted is the preferred mode of learning or demonstrating learning.

Many of the experiences provided in mainstream literacy and numeracy education have few, if any, links with the cultures and knowledge systems of remote Aboriginal cultures. Story telling is how histories are passed from one generation to the next so that 
written texts have little place in the lifeworlds of students. Similarly examples used to exemplify mathematical concepts and processes (such as MAB blocks that show base 10 number values or other resources) are not found in remote Australia. In contrast, most remote Aboriginal cultures are strong in music, dance and visual art. Building bridges between the home experiences and those offered in schools is a possible means for engaging learners and learning.

In the 1980s, research had been conducted across a number of cultural groups in the Northern Territory that mapped various aspects of the cultural knowledges of Aboriginal groups. For example, Harris (1984) mapped the annual calendar of Walpiri people to show how time was circular (rather than linear as represented in dominant mathematical representations) and was shaped by climatic conditions (as opposed to the passage of time as in Western measurements of time). Similarly, Helen Watson (Watson 1988; Watson and Chambers 1989) represented Yolgnu mapping protocols where she showed how Yolgnu people would sign the land as they traversed landscapes and that significant cultural events were used to sign the land. Maps were drawn that showed events rather than the landscape markers used in Western mapping protocols. These ethnographic approaches to documenting Aboriginal renderings of knowledge highlighted very different ways of understanding and representing worldviews. While such approaches have some promise, the reality is that in most remote Aboriginal communities in the Northern Territory, the average stay of a teacher is only 3 months, and the principal is about 12 months, so coming to learn the cultural knowledges of the local people is a significant challenge if the intent is to build local knowledges into the school curriculum.

Within the Australian contexts, many Aboriginal activists and educators are seeking an educational system that recognises the cultural biases of mainstream education whereby Aboriginal Australians are exposed to high standards of education where they are able to access dominant forms of knowledge and learning while at the same time ensuring that Aboriginal students are not compromised in their home cultures. This view is embodied in the quote from the Cape York Institute in Queensland, where the directors are clear in their objectives for education for Aboriginal learners to remain strong in their home cultures but able to access the knowledge and learnings from mainstream schooling:

Our younger generations will achieve their full potential, talent and creativity and have the confidence and capacity for hard work so that they can orbit between two worlds and enjoy the best of both. (Unknown 2010)

This view is currently referred to as a 'both-ways strong' education. Finding ways that engage Aboriginal learners in schools while ensuring cultural strengths are preserved is a challenge for current educational practice.

In many remote communities, particularly in secondary schooling, attendance is often low, irregular and sporadic, and perhaps is the most significant variable in teaching. Few remote Aboriginal students achieve the national requirement of $80 \%$ attendance. There are many reasons for the low attendance rates which include family obligations or what the Aboriginal people call 'business' which includes cultural events, funerals or sports events (which are a large part of community life). Not only does such business often require considerable time, there are often large distances to travel to other communities where these events may occur, thereby making the time away even longer. Often when in other communities, there may be other family 
business for which there may be obligations. Sporadic attendance creates challenges for teachers in terms of planning and teaching. These challenges create imperatives for teachers to develop teaching and learning strategies that address the very different teaching contexts of remote Australia from those found in urban settings. Within this context, teachers need to have some 'hooks' to try to attract students to school, then to keep them in school once they arrive, and then to engage them in learning.

More novel approaches are required that create a new space for curriculum. We suggest that the approaches that dominate traditional mathematics teaching in these areas have failed students and as a result, many Aboriginal students resist, actively or passively, engaging with the practices of school mathematics. As such, a new space (Moje et al. 2004) needs to be created that provides an engaging context with deep learning possibilities. This space differs from the usual practices of schooling but is also different from the home cultures of the students. This space creates new possibilities for learners.

The current model of schooling is one where there is an expectation that Aboriginal students will succeed in the school space, but this often leads to failure in school as well as a resistance to schooling from an Aboriginal space (Figure 1). When the cultures of the school and the families do not align, there is considerable space for resistance either overt or passive - where students fail to engage with the curriculum on offer. The consequences are manifested in the performance of students, including international and national testing as outlined at the beginning of this paper.

A new space is needed to create the possibilities of a both-ways strong curriculum. A curriculum space is needed where there is a strong academic curriculum that allows Aboriginal learners access to western ways of knowing and knowledge in a way that bridges the cultural divide, particularly when aspects of literacy and numeracy are not an integral part of the home culture. At the same time, the new space must allow for the incorporation of Aboriginal ways of learning and knowledge systems. This challenge is the foundation to this paper. This new space needed to draw on intellectual quality, particularly around literacy and numeracy, and on the interests of the students in ways that would engage them in the learning processes. We drew on their keen interest in music and multimedia, namely the digital games environment.

To this end, we draw on Gee's (2003) work which has shown how digital games have the potential to create new learning opportunities. Gee's work focused on learning environments and new forms of literacy. His work has highlighted that the games environment offers a challenging space that scaffolds learners through the game. As they progress through levels, they learn new skills that will be needed to be successful

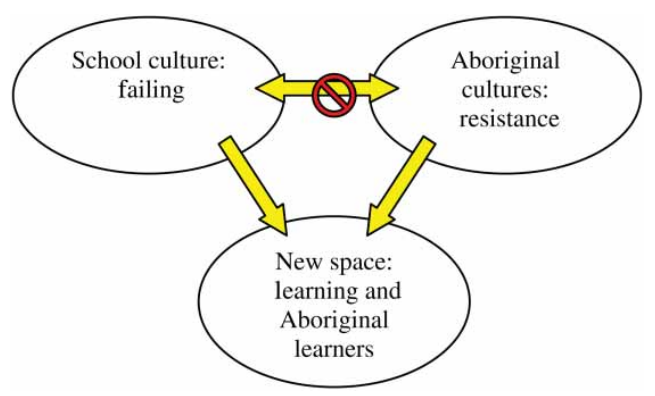

Figure 1. Creating a new space for learners. 
in the next level. Using their new learnings, they are able to succeed in subsequent levels but in so doing must also confront new challenges, apply and modify the skills learnt in earlier levels. This progressive learning and modifying skills is done in ways that are not public and that provide feedback to learners to enable them to move forward. Such learning principles are fundamental to games environments but less obvious in school environments, particularly mathematics. We find these principles of learning of particular value in contexts where students may be disengaging with learning and have applied them to a number of other contexts. Gee's work challenges conservative orthodoxies that have dominated education and advocates for the use of digital games to offer engaging learning environments that potentially offer rich learning experiences for disengaged learners. Careful selection of appropriate games is an implicit criterion for the use of games in the learning environment.

In this paper, we present the case from a remote secondary college where the use of a digital game was the catalyst to engage students in a range of learning activities that provided a bridge between the interests of the students and the knowledges valued within the school curriculum. In this way, it created a new space for learning - one that would capture the interests of the students and enable them to engage with school culture and knowledge. In developing the innovation, the strengths of the students were respected and drawn upon to capture interest and motivation. Such an approach draws on what Brousseau (1997) proposed when he argued that curriculum reform required that

the teacher must imagine and present to the students situations within which they can live and within which the knowledge will appear as the optimal and discoverable solution to the problems posed. (p. 22)

The school is in a very remote location in the Northern Territory in Central Australia. It is spread over three communities and is geographically dispersed over a distance of $450 \mathrm{~km}$ between the two furthest communities. Teachers are based in the remote communities but come to a central campus from time to time so that students can engage with each other in combined learning activities. The day-to-day teaching is offered in community so that students attend a local site. While the school may be secondary in age, all curriculum areas are taught by one teacher, similar to the teaching approach used in many primary schools. Mostly these are due to the teaching-student staffing ratios only allowing for one teacher in each site. There is a strong emphasis on literacy and numeracy with other curriculum areas being taught as well. There is a boarding facility at the central location so students come in to this site from time to time for focused teaching experiences. This often involves students from all three communities coming together. This structure is quite unique in terms of education provision but does create some new challenges in terms of curriculum dispersal and teacher professional learning.

\section{Digital media as a hook for learning}

Young people in general, and the students at this site in particular, are keenly interested in a range of digital media. This made the adoption and application of Gee's (2003) work particularly valuable in terms of what games environments offer to learners that is not evident in traditional teaching situations. To this end, the keen interest of students was used as the draw card to create a bridge between their worlds and that of 
schooling. The computer game 'Guitar Heroes' was identified as a medium through which the students' keen interest (and strength) in music could be built upon, using the game as the stepping stone. Guitar Heroes is described thus:

The Guitar Hero series (sometimes referred to as the Hero series) is a series of music video games first published in 2005 by RedOctane and Harmonix Music Systems, and distributed by Activision, in which players use a guitar-shaped peripheral to simulate the playing of lead, bass guitar and rhythm guitar across numerous rock music songs. Players match notes that scroll on-screen to colored fret buttons on the controller, strumming the controller in time to the music in order to score points, and keep the virtual audience excited. The games attempt to mimic many features of playing a real guitar, including the use of fast-fingering hammer-ons and pull-offs and the use of the whammy bar to alter the pitch of notes. Most games support single player modes, typically a Career mode to play through all the songs in the game, and both competitive and cooperative multiplayer modes. With the introduction of Guitar Hero World Tour in 2008, the game includes support for a four-player band including vocals and drums. The series initially used mostly cover version of songs created by WaveGroup Sound, but most recent titles feature soundtracks that are fully master recordings, and in some cases, special re-recordings, of the songs. Later titles in the series feature support for downloadable content in the form of new songs. (Wikipedia 2010, http://en.wikipedia. org/wiki/Guitar_Hero)

Guitar Heroes allows players to take on the roles of rock stars and to play instruments (guitars or drums) and to sing. There is a strong interest among many Aboriginal students in music so providing a medium that tapped into this interest and also which crossed into non-Aboriginal contexts supported the both-ways strong approach to curriculum design. The game offered many features that not only supported learning in the music area but also in other areas of the curriculum as well. The process for engaging with the game was that prompts appear on a screen and the player must be able to copy the cues from the game. As they move through the game, their performance is ranked. While there is a possibility to play on line, the game was confined to the classrooms.

The Guitar Heroes was taught through the Rich Task (Education Queensland 2000; Roulston 2000) process. A rich task is transdisciplinary, so by its very design it must incorporate a number of areas of the curriculum in valid and authentic ways. The activity should be authentic and connect to the worlds of the students so that they can see relevance and purpose in their learning. They are activities which extend over a period of time. In this case, this was over a full school term (10 weeks). Initially, teachers used the games as a motivational tool but progressively built richer experiences to extend the everyday interests in the game. With all Rich Tasks, there must be a final performance assessment item built in that represents the culmination of a range of learning experiences for the students. Using the Rich Task in this context, the performance assessment item was for the students to perform a musical item at the end of year concert. While the students have a strong interest in music, their cultural disposition is one of shyness and avoidance of public displays. As such, the Guitar Heroes was used to provide an avenue for the students to learn new material but in that process, their knowledge of performance would be developed. The Guitar Hero package captured both of these areas of learning. Through 'playing' the game, students would become explicitly aware of what makes quality performance which would then be built into their repertoire of skills. It was hoped that the use of the package would also act as a motivator to attract the students to attend and remain at school. It was also planned that the Guitar Heroes would provide a new space for learning in other 
curriculum areas, most particularly mathematics. The focus on mathematics was facilitated through the performance aspect of the game where students' scores would be displayed and hence provided a realistic catalyst for engaging with some significant mathematics.

At the end of the Rich Task, a concert was held at which students were expected to perform. Teachers and students were also interviewed to evaluate the success of the Rich Task in terms of implementation and student learning. In the remainder of this paper, we discuss the implications of this approach, including areas of learning that were facilitated through the use of the digital games environment.

We have coined the phrase 'learning beyond the game' to refer to learnings that are not the feature of the game but are brought about through engagement with the game. These learnings may be related to the cognitive aspects of the game and can relate to knowledge structures as well as processes. However, we also note that in the context of the game environment, these learnings may also relate to social and affective dimensions of learning.

\section{Guitar Heroes as motivation}

Attendance is a key issue in remote Aboriginal communities. Many students lag behind national benchmarks due to high absenteeism. Creating a learning environment that both attracts them to school and then keeps them at school is critical. Tapping into the students' keen interest in digital media and music was enabled through the use of the Guitar Heroes. This can be seen in the comments offered by teaching staff:

Troy: The students were riveted. A few were intimidated at first because they had no skills but they came in early to school to develop the skills with the guitars when there was no-one around.

Teachers often used tools for motivation but in remote areas, there is often a need for reward systems to encourage attendance over the day so that students remain in school for extended periods of time. In many remote communities, for example, where there are swimming pools, there are rules such as 'no school, no pool'. Some teachers adopted this approach through Guitar Heroes in order to keep students in school when they attended.

Mary: The students were very interested. Motivation to attend in the afternoons (when Guitar Heroes was available) increased. Behaviour improved as 'no classwork, no Guitar Heroes' was employed. Enthusiasm was maintained as the term went along. Bringing in the drum kit seemed to assist this as did the increasing confidence in skills.

Elise: The students were immediately interested. Not all were confident to try at first. It was a good motivational tool as there was an understanding that those who arrived early in the morning and worked on literacy and numeracy tasks would later be rewarded with Guitar Heroes.

Troy: Students just want to play it, they want a turn. They will come to school early and stay after school because the competition is too much during the day.

One of the challenges of working in remote communities is the 'revolving door' where students may come to school for a while, then go home or somewhere in community only to return later on. This is a very common phenomenon in these 
communities. Providing engaging activities that will keep the students at school for longer periods is paramount. The Guitar Hero package enabled teachers to do this.

Similarly, teachers commented on the impact of the package on behaviour. In this context, there is often an aggression not far below the surface in the social interactions of the young people where they are prone to physically hit out at people if they are frustrated or want something. Self-constraint is often challenged. Teachers remarked on how the students were able to watch and participate through observation.

Larry: Students reacted favourably to the Guitar Heroes. Spectators find it interesting as well. There is no arguing, pushing or rough behaviour in order to get a turn on an instrument.

Mary: Initially only the boys were playing as the girls were a bit wary but then the girls started to play as often as the boys. Factors that led to sustained interest was the increasing difficulty of the songs, playing levels and the introduction of the drum kit.

Larry: One boy, who is an excellent drummer, has had a big improvement in behaviour recently from being loud and distracted to a regular attendee who is motivated in literacy and numeracy. At one stage it looked like he may not be able to attend boarding (at the main campus) where the band practices with real musical gear. He treated the consequences seriously and seemed to have a picture of himself as an effective learner. He is the leading motivated learner amongst the fellas. ${ }^{1}$

While every attempt was made to seek input from the students as to their perceptions of the game, we were unable to solicit depth in their comments. In part, this is due to the cultural norms that operate in these communities where there is an expectation among students not to 'show off' their knowledge, learnings or feelings. So, while the comments were brief in form, they showed some insights into the students' perceptions. Students offered similar remarks that reinforced teachers' perceptions of their engagement and interest:

Student 1: It was fun because it was for the kids

Student 2: We felt happy when we were playing

Student 3: We felt strong

Student 4: It was fun because you can play Michael Jackson songs

Student 5: It was good playing Eye of the Tiger.

\section{Enhancing learning outcomes}

In order to redress the status quo in terms of poor learning outcomes for remote Aboriginal students, any learning experience must address key learning areas. Learning experience must focus on more than just entertainment. With Guitar Heroes, clearly learning about music and performance were integral to the package.

\section{Music}

Many of the students were interested in music but were self taught and hence had little explicit knowledge about music curriculum. Students who already had skills in rhythm picked up the skills of reading moving notes and synchronising the playing of the 
buttons and strings. Those without these skills seemed to experience the same enjoyment

Larry: While GH does not teach guitar, it does improve some of the skills needed of guitar playing - e.g. precision of timing, on-beat, off-beat rhythms; variation in melody and rhythm; left-hand four finger coordination; right and left hand coordination; the need to practice to improve. It also let the player experience the joy of holding and playing a musical instrument.

Elise: Playing the drum kit develops the same skills as needed for a real drum kit. It is less so with the guitars although they still have to learn to move the individual fingers on the left hand.

While in community, the students used Guitar Heroes as part of their music experiences as there were no instruments in the community campuses. However, when they came in for boarding, they were able to access the real instruments - drums and guitars as well as other percussion instruments. The musician-in-residence worked with the students on these instruments, thus reinforcing and extending their repertoire of skills and knowledges gained through Guitar Hero.

While the Guitar Heroes Rich Task was aimed towards enhancing performance through development of musical skills, it was also aimed at dispositions towards performance. In community, the teachers supported the students to perform in front of their peers at school as well as performing in community. The latter was more or less successful depending on the different communities. However, when the three communities came together, there was very little evidence of a willingness to engage in public performance. This skill may take longer to develop due to the entrenched culture of non-displays of superior behaviour. In these communities, there is an unwillingness to show others how much an individual knows as this may cause shame to the others who know less. This cultural feature is very strong in these communities so understandably this was not a learning outcome from this Rich Task.

\section{Building social skills}

The Guitar Heroes format is one of a band playing cooperatively. Teachers often bemoaned the poor social skills of their students, most particularly, their willingness to collaborate with peers. Often there were physical confrontations when some form of collaborative effort was required. As teachers indicated, the necessity of having to work as a team (i.e. a band) provided a strong incentive to work collaboratively. There were considerable examples in the teachers' reflections on the capacity of the package to develop a range of social skills.

Larry: Apart from football, it is uncommon for collaboration to occur at other times for these students. Collaboration and community was very high when they were playing.

Mary: One girl with good skills talking another one through how to play the game. It was very cooperative.

Troy: Students shared the guitars with no arguments

The cultural norms of the group were an important aspect of social engagement. As noted earlier in the paper, gender segregation is a key feature in home culture. 
One teacher reported that once he split the students into gendered groups, the social interactions were greatly enhanced.

Larry: There has been significant social engagement. We have since separated students into gender groups and found that the classroom behaviour is much better. It is possible structured interaction is more affirming and safe than 'hangin out' together in the classroom where loud and distracting behaviour is the norm.

Another teacher also commented on the capacity of the game to facilitate social groups and interaction more than is often possible with other approaches used in the classroom. She even commented that passive involvement occurred, which was very unusual for this group of students.

Mary: Social engagement has increased as the game is more of a group activity than say computers. Though active participation for all the students was difficult due to only having one band set, many of the students were interested in watching the others. Cooperation was good and students voluntarily took it in turn to play the guitars and drums.

From the teachers' comments, it appears that the Guitar Heroes environment offered considerable potential to create learning environments that fostered strong social interaction and collaboration. This was an intended learning outcome but was one that the teachers valued and had had considerable challenges in creating in other learning experiences they had tried to foster.

\section{Extending learning beyond music and performance}

While the game offered potential for learning about music and performance, teachers, as part of the Rich Task approach, must develop key learnings in other areas that are pertinent to the key activities. In this case, the teachers extended into areas of literacy and numeracy.

In one community, the teacher used Guitar Heroes as a basis for studying percentages. The study of percentages is often in the context of marking up prices or growths. Trying to find meaningful contexts for percentages in remote communities is difficult. Guitar Heroes was an enabling tool for this aspect of mathematics education. Using the scores that students gained, the teacher recorded scores and students discussed changes in scores, what may be causing them, and how they may be improved. The scores were entered into spreadsheets and turned into graphs so that there was a considerable extension beyond the game into other curriculum areas.

Mary: Guitar Hero seems to demand rhythm skills more than other aspects of musical performance. You are essentially 'marked' on your ability to pick up the rhythm of a song, more than, for example, on the melody. The scores/percentages at the end encourage criticism of performance and a desire to improve. Also, the students learn more songs from the Guitar Heroes repertoire and sing along.

Here Mary provides a rationale for the use of Guitar Heroes to link to the interests and motivations of the students (to improve performance) using the scores obtained by the students as a catalyst for the intervention. These scores were numerical representations of their performance and so provided a personally meaningful context for the use of number. 
Elise: We based a few classes on Guitar Hero scores - such as percentages of 100, score charts, and Excel bar graphs. From a Maths perspective, Guitar Heroes provided a basis for lessons. At the same time it encouraged improvement. Students might say, 'Hey look I got 92\%' which then encouraged cooperation and group focus as they tried to work out what worked and what made it better.

Another community used the Guitar Heroes to extend into critical literacy activities by using the 'hero' metaphor as the launchpad into activities around identity and voice of marginalised social groups:

Larry: The Guitar Heroes provided a ready reference for thinking about fame and being a 'pop star'. It provided a good context for considering critical literacy with such matters as who has identity and voice. This has been extended into thinking about identity and voice with Aboriginal (Anangu) people and other minorities in Australia.

\section{Creating a 'third space'}

The use of the Guitar Heroes games provided a new space for learning. Using the media as a tool to engage learners in areas that were of a strong interest - music and digital environments - teachers were able to provide a rich experience for the students. In communities where there are low levels of literacy and numeracy representations, finding opportunities for teaching many concepts is elusive.

Often schooling is seen as a binary opposition in relation to the home culture of Aboriginal students; the culture of the school versus the culture of the home. What we have attempted in this project is to draw from Soja (1996) to create a new space that selectively and strategically draws from the two oppositional categories to create a new alternative. By creating a new space that builds bridges between the two diverse cultural spaces, a new educational space has been created. Effectively, this new space has created new opportunities for students who are otherwise marginalised from school learning. The data provided in this paper have shown how this third space has allowed for greater academic and social engagement of Aboriginal students in learning and implicitly for greater success in school.

An alternative to seeing the third space as a place that builds bridges between two cultural spaces is to view the third space as a place of border crossings. In this interpretation of the third space, students are able to enjoy successes in a new community. For Aboriginal students, coming to school requires significant changes to be incorporated into their repertoire of practices in order for them to be successful. In formal schooling the success in these border crossings has been minimal. However, by creating a third space where there is an intermediary space in which the students can engage with aspects of the school space but with aspects of their home space, the third space enables them to cross into this school space with greater ease. By creating synergies with the everyday knowledges of the students, in this case music and digital media, the students have been provided with opportunities to engage with the knowledge of schools (numeracy, literacy, work ethics, etc.).

It was not our intention in this paper to provide a critique of the cultural space of the Aboriginal students and seek ways to transcend the non-recognition of Aboriginal knowledges in the curriculum. Our goal was to create a third space 
that would provide both a bridge to formal school knowledge while scaffolding students to enable them to undertake boundary crossings successfully. By creating a space where students could make connections between their personal interests and with concepts within school culture, with that of their own interests, we have shown that there are many benefits for education provision. Curriculum offerings have not been compromised but rather enhanced. In remote communities where these synergies are minimal at best, and most often non-existent, creating a third space that enables the explicit linking of knowledges may provide a pathway for Aboriginal students into the formal learnings represented in school curriculum.

\section{Note}

1. Fellas is a term used by local communities for young men who have passed through cultural rituals to become men. However, they may be as young as 12 through to 15 so the term is used to denote their status in the culture but also to recognise their youth.

\section{Notes on contributors}

Robyn Jorgensen is Professor of Education at Griffith University. She is a Senior Fellow of the Griffith Institute for Educational Research. Her research has focused on issues of equity and access with a particular focus on working-class, rural and remote, and Indigenous learners. She took leave from the University in 2009-2010 to work in remote Central Australia as $\mathrm{CEO}$ /Principal of an Aboriginal College. Her work focuses on practice and how it is implicated in the marginalisation of students. She works to address such practices to enable greater inclusion of students who are traditionally marginalised from schooling.

Professor Tom Lowrie is the Director of the Research Institute for Professional Practice, Learning and Education at Charles Sturt University. Tom has taught in a number of primary school and university settings (including Australia, Canada and the USA) over the past 20 years. A large body of his research has investigated the extent to which communication technologies impact on the education community including teachers, children, and their parents, as well as children's mathematics engagement in out-of-school settings.

\section{References}

De Bortoli, L., and S. Thomson. 2009. The achievement of Australia's indigenous students in PISA 2000-2006. Melbourne: ACER Press.

Brousseau, G. 1997. Theory of didactical situations in mathematics. Dordrecht, The Netherlands: Kluwer.

COAG Reform Council. 2010. National indigenous reform agreement: Baseline performance report for 2008-09. Sydney: COAG Reform Council.

Education Queensland. 2000. New basics: Theory into practice. Brisbane: GoPrint.

Gee, J.P. 2003. What video games have to teach us about literacy and learning. New York: Plagave MacMillan.

Harris, P. 1984. Teaching about time in tribal aboriginal communities. Darwin: Department of Education.

Harris, S. 1994. 'Soft' and 'hard' domain theory for bicultural education in Indigenous groups. Peabody Journal of Education 69: 140-53.

Moje, E.B., K.M. Ciechanowski, K. Kramer, L. Ellis, R. Carrillo, and T. Collazo. 2004. Working toward a third space in content area literacy: An examination of everyday funds of knowledge and discourse. Reading Research Quarterly 39, no. 1: 38-70.

Roulston, J. 2000. The new basics: Education for the 21st century. Practising Administrator 22, no. 4: $12-14,44$.

Soja, E.W. 1996. Thirdspace: Journeys to Los Angeles and other real and imagined places. Malden, MA: Blackwell. 
Unknown. 2010. Cape York partnerships: Education stream. http://www.capeyorkpartnerships. com/academy.

Watson, H. 1988. Language and mathematics education for Aboriginal-Australian children. Language and Education 2, no. 4: 255-73.

Watson, H., and D.W. Chambers. 1989. Singing the land, signing the land. Geelong: Deakin University Press. 